\title{
An important role for glutathione and $\gamma$-glutamyltranspeptidase in the supply of growth requirements during nitrogen starvation of the yeast Saccharomyces cerevisiae
}

\author{
Karim Mehdi and Michel J. Penninckx \\ Author for correspondence: Michel J. Penninckx. Tel: +3223733303 . Fax: +3223733174 \\ e-mail : upemulb@resulb.ulb.ac.be
}

Laboratoire de Physiologie et Ecologie Microbiennes, Section Interfacultaire d'Agronomie, Université Libre de Bruxelles c/o Institut Pasteur, Rue Engeland 642, B-1180, Brussels, Belgium

Keywords: yeast, glutathione, $\gamma$-glutamyltranspeptidase, nitrogen starvation, vacuoles

\section{INTRODUCTION}

Glutathione (GSH; L- $\gamma$-glutamyl-L-cysteinylglycine) is present in high concentration in most living cells from micro-organisms to man, and has been shown to play numerous roles, in particular in the yeast Saccharomyces cerevisiae, where it may account for $1 \%$ of the cell dry weight (Penninckx \& Elskens, 1993). A role of GSH as an endogenous sulphur source in $S$. cerevisiae has previously been shown (Elskens et al., 1991). In this yeast, GSH catabolism appears to be mediated by $\gamma$ glutamyltranspeptidase $(\gamma-\mathrm{GT})$ and cysteinylglycine dipeptidase, and leads to the formation of glutamate, cysteine and glycine (Jaspers et al., 1985). Yeast $\gamma$-GT biosynthesis was found to be regulated by at least two apparently distinct pathways involving, respectively, repression by ammonium ion (Penninckx et al., 1980) and GSH (Elskens et al., 1991). Repression of $\gamma$-GT by $\mathrm{GSH}$ is related to the sulphur storage function of GSH (Elskens et al., 1991). In contrast, no clear physiological function was attributed to the repressive effect of the ammonium ion. A possible role for $\gamma-\mathrm{GT}$ in the bulk transport of amino acids by $S$. cerevisiae (Penninckx et

Abbreviations: $\quad$ BSO, buthionine- $(S, R)$-sulphoximine; $\gamma$-GCS, $\gamma$ glutamylcysteine synthase; $\gamma$-GT, $\gamma$-glutamyltranspeptidase; SBM, standard basal medium. al., 1980) was later contradicted (Robins \& Davies, 1981; Jaspers \& Penninckx, 1981; Payne \& Payne, 1984). Here we show that nitrogen starvation induced a migration of more than $90 \%$ of GSH towards the central vacuole (tonoplast) of the yeast cell. This migration was accompanied by a de novo synthesis of the tripeptide and a derepression of $\gamma$-GT. GSH that had accumulated in the central vacuole was further degraded and seems to play the role of a reservoir to provide the yeast cell with amino acids for subsequent growth requirements.

\section{METHODS}

Strains. The wild-type strain $\Sigma 1278 b$ (MATa), was described by Grenson et al. (1966) and obtained from the Laboratoire de Microbiologie de l'Université libre de Bruxelles. The GSHdeficient mutant ( $g s h A-2$ ) yeast strain was from our laboratory (Elskens et al., 1991).

Growth experiments. Orbital shake batch cultures $\langle 0.5$ and 11 ) were inoculated from aerobic, stationary-phase, glucosegrown precultures and incubated overnight at $29^{\circ} \mathrm{C}$ to obtain $S$. cerevisiae cells in the exponential growth phase. A mineral medium (M 165) with 3\% (w/v) glucose added as sole source of carbon, and containing vitamins and trace minerals but no nitrogen source, was used as the standard basal medium (SBM) (Messenguy, 1976). In the experiments on nitrogen starvation, cells of $S$. cerevisiae previously grown in SBM with 
$10 \mathrm{mM}\left(\mathrm{NH}_{4}\right)_{2} \mathrm{SO}_{4}$ as the nitrogen source (minimal medium) were harvested at $0 \cdot 4-0.5 \mathrm{mg}$ dry wt $\mathrm{ml}^{-1}$ by rapid Millipore filtration $(0.45 \mu \mathrm{m}$ HAWP), washed twice with SBM and transferred to the same medium.

Enzyme and protein assays. Cells were harvested at $4{ }^{\circ} \mathrm{C}$ by centrifugation at $6000 \mathrm{~g}$ for $10 \mathrm{~min}$, washed twice with an appropriate buffer for the enzyme determination and resuspended in the same buffer. The cells were ruptured by sonication for $10 \mathrm{~min}$ with a Vibra cell VC 500 ultrasonic processor (Sonics Materials). The homogenate was centrifuged ( $27000 \mathrm{~g}$ for $15 \mathrm{~min}$ ) and the supernatant fluid was used as the enzyme source.

GSH synthase (EC 6.3.2.3) and $\gamma$-GT (EC 2.3.2.2) were assayed according to Jaspers et al. (1985). $\gamma$-Glutamylcysteine synthase $(\gamma-\mathrm{GCS} ; \mathrm{EC}$ 6.3.2.2) was assayed following Kistler et al. (1990).

Protein was estimated by the Lowry method using bovine serum albumin as standard. Enzyme units (U) were expressed as nmol product $\mathrm{h}^{-1}$. Specific activities were $\mathrm{U}$;mg protein $)^{-1}$.

Determination of metabolic intermediates. The method of Sakaguchi was adapted for the determination of the cell content of arginine of $S$. cerevisiae (F. Ramos, personal communication). All reagents were kept at $0{ }^{\circ} \mathrm{C}$ and added, with mixing each time, in the following sequence: $2 \mathrm{ml}$ sample (25-400 nmol arginine), $0.25 \mathrm{ml} 40 \% \mathrm{NaOH}, 0.1 \mathrm{ml} 0.2 \%$ recrystallized $\alpha$-naphthol ( $1 \%$ in ethanol diluted fivefold with water) with immediate mixing. After $15 \mathrm{~min}$ incubation, $0.5 \mathrm{ml}$ hypobromite reagent was added $\left(5 \mathrm{ml} \mathrm{Br}_{2}\right.$ per $100 \mathrm{ml}$ $10 \% \mathrm{NaOH})$. After exactly $10 \mathrm{~s}, 10 \mathrm{ml} 95 \%$ ethanol was added at $0{ }^{\circ} \mathrm{C}$ with immediate mixing, followed by $1 \mathrm{ml} 40 \%$ $(\mathrm{w} / \mathrm{v})$ urea. Absorbance at $520 \mathrm{~nm}$ was stable for at least $1 \mathrm{~h}$.

GSH was estimated according to Eyer \& Podhradsky (1986), or alternatively by the modified Fahey procedure described by Elskens et al. (1991) as indicated in the text.

Total and differential pool extraction. A standard procedure (Ramos et al., 1970) was used for the extraction of total GSH and amino acid pools in $S$. cerevisiae. The cytoplasmic and vacuolar pools were extracted following the method of Ohsumi et al. (1988). Briefly, this method was based on the specific loss of the permeability barrier of the plasma membrane of the yeast cell in the presence of cupric ion $\left(\mathrm{Cu}^{2+}\right)$. The cytoplasmic content of metabolic intermediates was estimated on the leakage fluid. The vacuolar content was then estimated by extraction of the $\mathrm{Cu}^{2+}$-permeabilized yeast with boiling water or trichloroacetic acid. The validity of the differential extraction procedure was checked for the $S$. cerevisiae strains used in the present investigation. Cells of the $\Sigma 1278 \mathrm{~b}$ and gsh-A2 strains growing in minimal medium were harvested at $0.5-0.6 \mathrm{mg}$ dry wt $\mathrm{ml}^{-1}$ and extracted according to the Ohsumi method; $95 \pm 1.2$ and $49.8 \pm 0.9 \%$ (mean \pm SD; $n=3$ ) of the respective arginine and GSH pools were found to be associated with the vacuolar compartment. These values are close to the data of Messenguy et al. (1980) and Jaspers \& Penninckx (1984), obtained by a completely different extraction procedure using cytochrome $c$. Respective values of $59 \cdot 1 \pm 2 \cdot 3$ and $7 \cdot 1 \pm 1 \mathrm{nmol}(\mathrm{mg} \mathrm{dry} \mathrm{wt})^{-1}$ were found for the total pools of arginine and GSH of $\Sigma 1278 \mathrm{~b}$, by the standard extraction procedure mentioned above. By summing the respective values obtained for the cytoplasmic and vacuolar pools by the differential procedure, total respective values of $58.9 \pm 2.6$ and $6.9 \pm 1 \cdot 1 \mathrm{nmol}(\mathrm{mg} \mathrm{dry} \mathrm{wt})^{-1}$ were obtained for arginine and GSH.

Reproducibility of results. Only single values are quoted in the figures illustrating this paper. However, experiments are only reported that were repeated at least twice and that gave consistent results. Standard deviations were all within $10 \%$ of the mean values presented.

\section{RESULTS}

\section{Effect of nitrogen starvation on the total GSH pool}

In cells of $\Sigma 1278 \mathrm{~b}$ growing exponentially on minimal medium, the total pool of GSH accounted for $7 \pm 1 \mathrm{nmol}$ (mg dry wt $)^{-1}$ (Elskens et al., 1991). When cells were transferred from minimal medium to SBM devoid of nitrogen source, the total GSH pool increased gradually during the next $2 \mathrm{~h}$, culminating at $17 \cdot 2 \pm 1.3 \mathrm{nmol}(\mathrm{mg}$ dry $w)^{-1}$ (Fig. 1a). The GSH pool decreased subsequently to attain a stable value of $2 \cdot 6 \pm 0 \cdot 3 \mathrm{nmol}$ $(\mathrm{mg} \text { dry wt })^{-1}$ after $2 \mathrm{~h}$. When cells of $S$. cerevisiae were taken from and returned to minimal medium, the value of the GSH pool remained constant (Fig. 1a). The GSH pools determined by the procedure of Eyer \& Podhradsky (1986) were very close to the values obtained by the HPLC procedure of Fahey (see Methods), indicating no interfering thiol in the enzyme method used routinely in this investigation.

As reported by several authors, the nitrogen status of a culture medium of yeast may influence the distribution
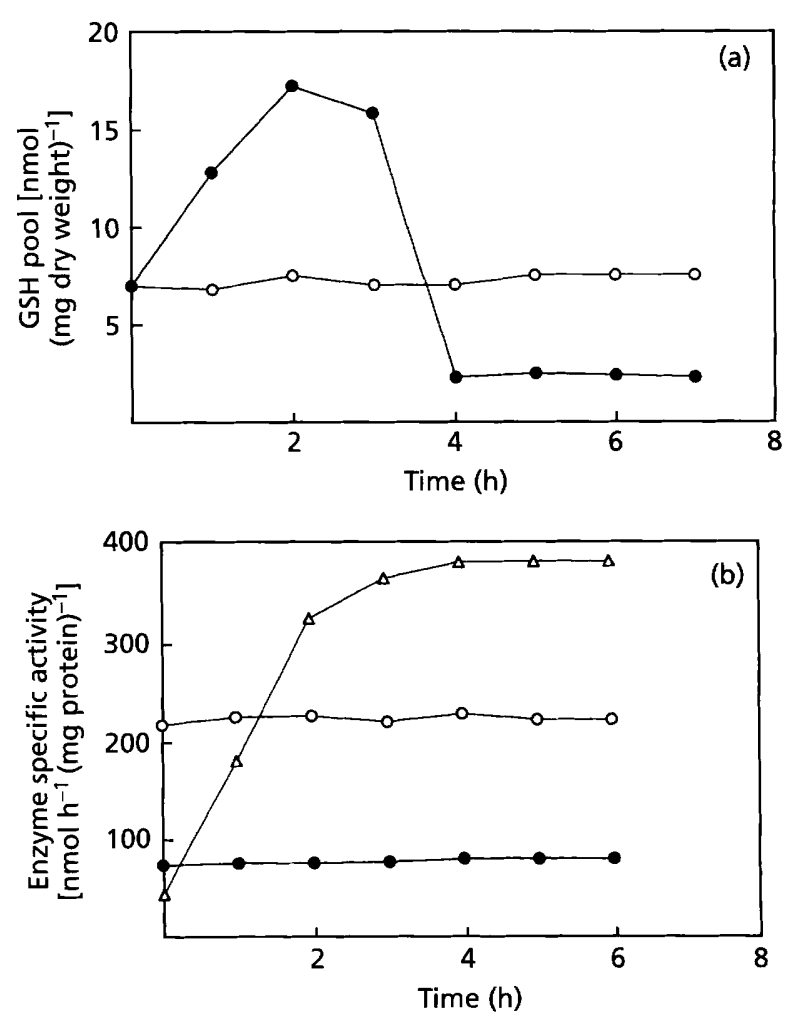

Fig. 1. Effect of nitrogen starvation on the total intracellular pool of GSH and enzymes implicated in GSH metabolism. (a) At time zero cells of $\Sigma 1278 \mathrm{~b}$ were transferred into nitrogendeficient SBM (O) or to minimal medium (O). (b) Effect of nitrogen starvation on the specific activities of $\gamma$-GCS (0), GSH synthase $(O)$ and $\gamma$-GT $(\triangle)$. 

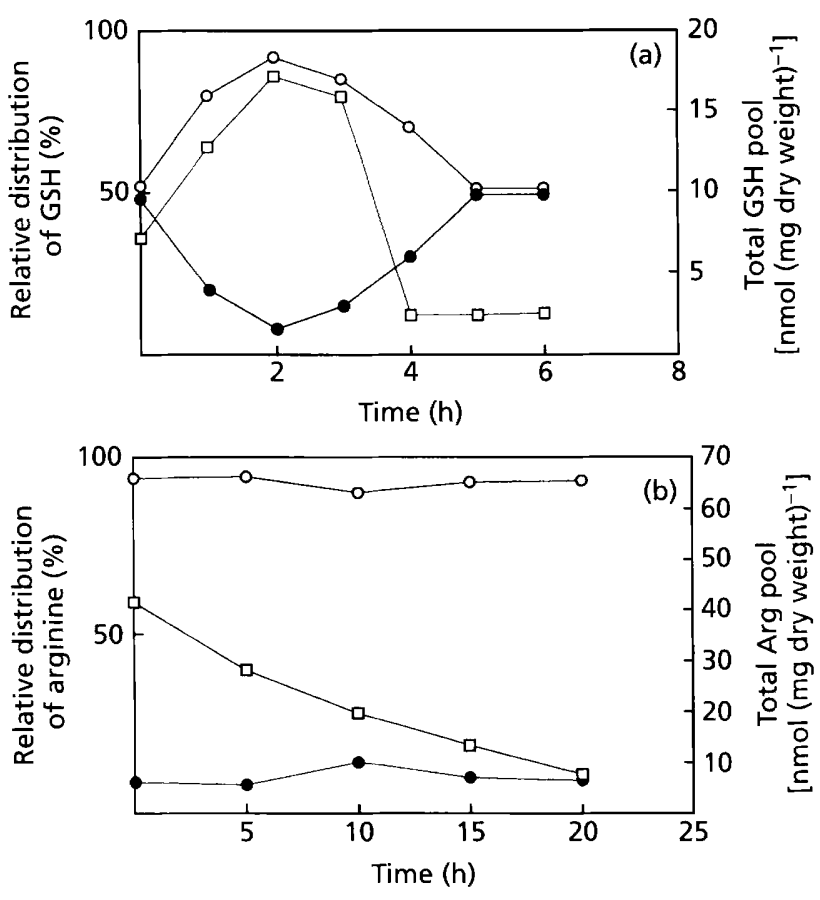

Fig. 2. Effect of nitrogen starvation on the differential pools of GSH and arginine in the yeast strain $\Sigma 1278 b$. (a) Relative distribution of GSH between the central vacuole $(0)$ and the cytoplasm (e). $\square$, Evolution of the total pool. (b) Relative distribution of arginine. $O$. Central vacuole; 0 , cytoplasm; $\square$, evolution of the total pool.

of metabolites between the cytoplasm and central vacuole (Messenguy et al., 1980; Kitamoto et al., 1988). The effect of nitrogen deprivation on the repartition of GSH between the cytoplasm and the vacuole was thus examined.

\section{Differential pool changes}

As shown in Fig. 2(a), nitrogen starvation was associated with a shift of more than $90 \%$ of the GSH towards the vacuole. The subsequent consumption of GSH during nitrogen starvation was about $90 \%$ of the accumulated thiol tripeptide. Both cytoplasmic and vacuolar GSH decreased to stable values of around $1.3 \mathrm{nmol}$ (mg dry $\mathrm{wt})^{-1}$.

The effect of nitrogen starvation on the arginine pool was also tested for comparative purposes. During nitrogen starvation, the total pool of arginine decreased in the first $2 \mathrm{~h}$ from $59 \cdot 1$ to $52 \cdot 1 \mathrm{nmol}(\mathrm{mg} \mathrm{dry} \mathrm{wt})^{-1}$ and to $11.6 \mathrm{nmol}(\mathrm{mg} \mathrm{dry} \mathrm{wt})^{-1}$ after $20 \mathrm{~h}$ (Fig. 2b). As indicated above, about $95 \%$ of arginine was confined to the vacuolar space. In contrast to GSH, there was no repartition of arginine between the cytoplasmic and vacuolar compartments during nitrogen starvation. Arginine stored in the vacuole was apparently utilized for growth during nitrogen deprivation, as has also been shown for other $S$. cerevisiae strains (Kitamoto et al., 1988).
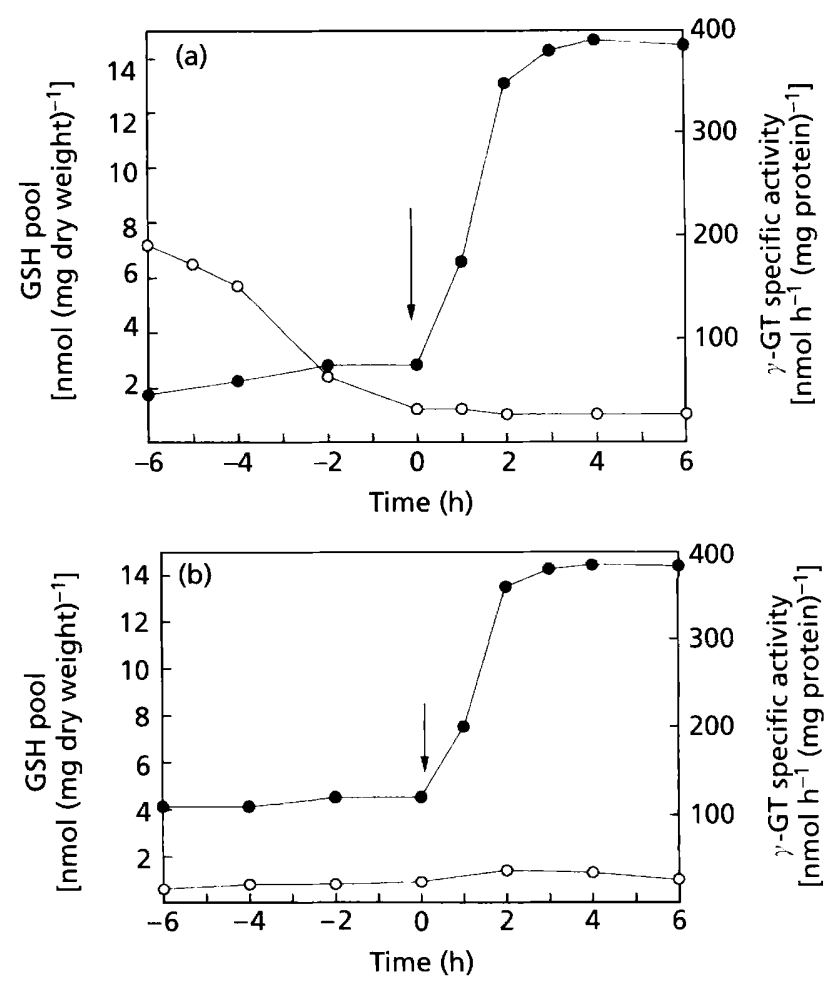

Fig. 3. Effect of inhibition of GSH biosynthesis on the levels of GSH and $\gamma$-GT (a) Effect of BSO. The arrow indicates introduction of BSO into SBM. O, Pool of GSH; 0 , specific activity of $\gamma$-GT. (b) The same experiment but with the mutant strain deficient in $\gamma$-GCS. O. Pool of GSH; 0 , specific activity of $\gamma-\mathrm{GT}$.

\section{Enzymes of GSH metabolism in relation to nitrogen starvation}

Nitrogen starvation had no apparent effect on the specific activities of $\gamma$-GCS and GSH synthase, both enzymes implicated in the biosynthesis of GSH (Fig. 1b). In contrast, the specific activity of $\gamma$-GT increased under nitrogen deprivation from a value of 45 to $380 \mathrm{U} / \mathrm{mg}$ protein $)^{-1}$ after $3-4 \mathrm{~h}$ starvation. This observation is in accordance with previous results on the repressive effect of ammonium ion (Penninckx et al., 1980) and GSH (Elskens et al., 1991) on $\gamma$-GT. $\gamma$-GT is the first enzyme of the degradation pathway of GSH (Jaspers et al., 1985; Jaspers \& Penninckx, 1985), and is most probably responsible for the decrease in GSH (Figs 1 and 2). The effect of selective inhibition of GSH biosynthesis during nitrogen starvation was studied in order to evaluate the physiological implications of the transient accumulation of the thiol tripeptide.

\section{Effects of the inhibition of GSH biosynthesis}

Buthionine- $(S, R)$-sulphoximine (BSO), a specific transition-state inhibitor of $\gamma$-GCS (Griffith \& Meister, 1979) lowered the level of GSH in S. cerevisiae (Elskens et al., 1991). Cells growing in minimal medium 


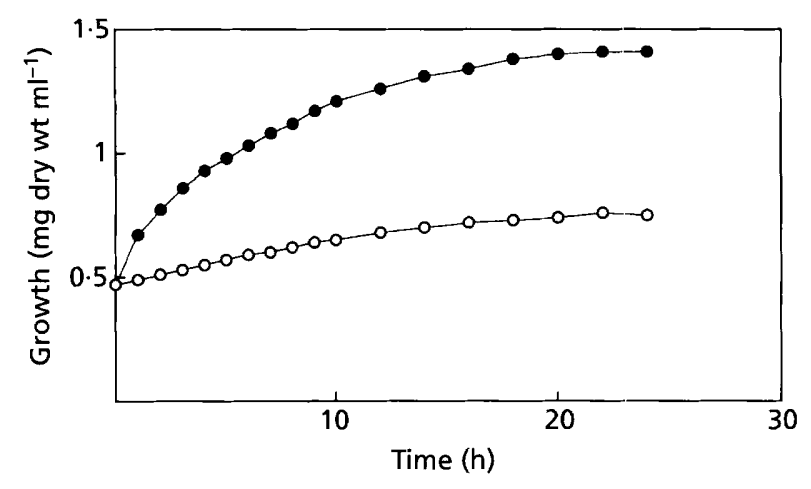

Fig. 4. Effect of nitrogen starvation on growth. Cells were grown initially in minimal medium in order to attain a dry weight of $0.5-0.6 \mathrm{mg} \mathrm{ml}^{-1}$. At time zero the cells were transferred into SBM. Growth of $\Sigma 1278 b$ wild-type ( $)$ and $\gamma$ GCS-deficient strain (O) were compared.

$\left(0 \cdot 1-0 \cdot 15 \mathrm{mg}\right.$ dry wt $\left.\mathrm{ml}^{-1}\right)$ were pretreated for $6 \mathrm{~h}$ with $1 \mathrm{mM}$ BSO in order to attain a residual intracellular concentration of $1.0 \mathrm{nmol} \mathrm{GSH}(\mathrm{mg} \mathrm{dry} \mathrm{wt})^{-1}$, and transferred to the nitrogen-deprived SBM supplemented with $1 \mathrm{mM}$ BSO. As shown in Fig. 3(a), no transient stimulation in GSH biosynthesis was observed. At time zero of the transfer procedure, the specific activity of $\gamma$ G'T attained $75 \mathrm{U}$ (mg protein $)^{-1}$, coming from a basal value of $45 \mathrm{U}$, observed characteristically on the minimal medium (Penninckx et al., 1980). This higher value reflected the enzyme derepression caused by the lowering of intracellular GSH (Elskens et al., 1991). $\gamma$-GT attained a maximal value of $380 \mathrm{U}$ (mg protein) $)^{-1}$ after about $4 \mathrm{~h}$ nitrogen starvation (Fig. 3a). A very similar pattern was obtained with the gshA-2 mutant strain defective in $\gamma$ GCS and having a residual GSH pool of $0.5 \mathrm{nmol}(\mathrm{mg}$ dry $w t)^{-1}$ (Fig. 3b). These experiments support the hypothesis that the pathway of GSH biosynthesis is responsible for the de novo tripeptide increase, and additionally that the repressive effects of GSH and ammonium ion are independent.

\section{Effect of nitrogen starvation on cell growth}

During nitrogen starvation, cells of $S$. cerevisiae increased threefold in dry weight (Fig. 4), which corroborated previous observations (Johnston et al., 1977). In contrast, when GSH biosynthesis was blocked either by mutation or by BSO (not shown), the increase was only $40 \%$ of the initial value at time zero of starvation (Fig. 4). This last observation points to a major role for GSH in the supply of growth requirements during nitrogen starvation.

\section{DISCUSSION}

The response of GSH to starvation seems to depend on the nature of the nutrient deprivation. When the yeast was deprived of sulphate, $\gamma$-GT was derepressed twofold and $90 \%$ of the total GSH pool (cytoplasmic and vacuolar) was consumed in about two cell generations (Elskens et al., 1991). In contrast to the situation encountered in nitrogen deprivation, no transient stimulation of GSH biosynthesis and special migration to the vacuole was observed during sulphur starvation. The de novo biosynthesis of GSH observed after nitrogen starvation could be explained by the increase of the flux of the tripeptide towards the vacuole, causing a relief of the feedback inhibition of $\gamma$-GCS by GSH (Meister $\&$ Anderson, 1983; Elskens et al., 1991).

The central vacuole in the yeast has been identified as an important storage area, and several transport systems of amino acids and ions using channels or pumps have been identified in this organelle (Garrill, 1994). Less information is, however, currently available concerning GSH transporters. A GSH transport system appearing under sulphur deficiency was detected several years ago in the fungus Penicillium chrysogenum (Hunter \& Segel, 1971). A recent study has identified the $S$. cerevisiae gene YCF1 as coding for a vacuolar glutathione $S$-conjugate transporter. The protein is a member of the ATPbinding cassette (ABC) family, has similarity to human multidrug resistance protein and was found to confer cadmium resistance on the yeast (Szczypka et al., 1994). Nothing is known about a possible relationship between the YCF1 protein and the putative GSH vacuolar transporter identified here. Moreover, the activity or/and biosynthesis of the putative GSH transporter would be sensitive to the ammonium ion, as for example observed for a plasma-membrane general amino acid permease (Grenson et al., 1970). S. cerevisiae $\gamma-G T$, which appears mainly as a membrane-bound enzyme associated with the central vacuole (Jaspers \& Penninckx, 1984), might function as an 'exit gate' for the GSH located inside the tonoplast in a manner similar to that illustrated in an early model of renal amino acid transport (Meister, 1973).

As has also been observed for mobilization of GSH as an endogenous source of cysteine (Elskens et al., 1991), only about $90 \%$ of the GSH pool was consumed during nitrogen starvation. S. cerevisiae thus seems to have developed a general mechanism preventing complete depletion of GSH. A dramatic decrease of yeast viability was in fact observed when the GSH pool dropped below a critical level corresponding to $1 \%$ of the wild-type value (Kistler et al., 1986).

Among the environmental parameters that commonly modulate the properties of microbial cells in nature, the concentration of macronutrients is of particular importance (Nyström, 1993). Micro-organisms are routinely exposed to macronutrient insufficiency (Morita, 1993). Previous investigations (Johnston et al., 1977) suggested that the degradation of intracellular macromolecules (RNA and proteins) could supply most of the growth requirements of the yeast during nitrogen starvation. The conclusions of this investigation were based mainly on the fact that both RNA and proteins were extensively degraded during nitrogen starvation. Macronutrient limitation, in particular of nitrogen, is a 
complex stress involving a global control system (Gottesman, 1984) where multiple unlinked genes are co-ordinately controlled by a common regulatory signal. As shown here, the vacuolar storage and further catabolism of GSH seems also to play an important and previously unsuspected role in the response of the yeast to the nitrogen stress.

\section{ACKNOWLEDGEMENTS}

Many thanks are addressed to F. Ramos and Ch. Jaspers for useful discussions.

\section{REFERENCES}

Elskens, M. T., Jaspers, C. \& Penninckx, M. J. (1991). Glutathione as an endogenous sulphur source in the yeast Saccharomyces cerevisiae. J Gen Microbiol 137, 637-644.

Eyer, P. \& Podhradsky, D. (1986). Evaluation of the micromethod for determination of glutathione using enzymic cycling and Ellman's reagent. Anal Biochem 153, 57-66.

Garrill, A. (1994). Transport. In The Growing Fungus, pp. 163-181. Edited by N. A. R. Gow \& G. M. Gadd. London: Chapman \& Hall.

Gottesman, S. (1984). Bacterial regulation: global regulatory networks. Annu Rev Genet 18, 415-441.

Grenson, M., Mousset, M., Wiame, J. M. \& Bechet, J. (1966). Multiplicity of the amino-acid permeases in Saccharomyces cerevisiae. Evidence for a specific arginine-transporting system. Biochim Biophys Acta 127, 325-338.

Grenson, M., Hou, C. \& Crabeel, M. (1970). Multiplicity of the amino acid permeases in Saccharomyces cerevisiae. J Bacteriol 103, 770-777.

Griffith, O. W. \& Meister, A. (1979). Potent and specific inhibition of glutathione synthesis by buthionine sulphoxime ( $S$-nbutylhomocysteine sulphoxime). J Biol Chem 254, 7558-7560.

Hunter, D. R. \& Segel, I. H. (1971). Acidic and basic amino acid transport systems in Penicillium chrysogenum. Arch Biochem Biophys 144, 168-183.

Jaspers, C. \& Penninckx, M. (1981). On the role of glutathione in the transport of amino acid in the yeast Saccharomyces cerevisiae: contradictory results. FEBS Lett 132, 41-44.

Jaspers, C. \& Penninckx, M. (1984). Glutathione metabolism in the yeast Saccharomyces cerevisiae. Evidence that $\gamma$ glutamyltranspeptidase is a vacuolar enzyme. Biochimie 66, 71-74.

Jaspers, C. \& Penninckx, M. J. (1985). Molecular and kinetic properties of purified $\gamma$-glutamyltranspeptidase from yeast Saccharomyces cerevisiae. Phytochemistry 24, 1913-1918.

Jaspers, C., Gigot, D. \& Penninckx, M. J. (1985). Pathways of glutathione degradation in the yeast Saccharomyces cerevisiae. Phytochemistry 24, 703-707.

Johnston, G. C., Singer, R. A. \& McFarlane, S. (1977). Growth and cell division during nitrogen starvation of the yeast Saccharomyces cerevisiae. J Bacteriol 132, 723-730.
Kitamoto, K., Yoshizawa, K., Oshumi, Y. \& Anraku, Y. (1988). Dynamic aspects of vacuolar and cytosolic amino acid pools of Saccharomyces cerevisiae. J Bacteriol 170, 2683-2686.

Kistler, M., Summer, K. H. \& Eckardt, F. (1986). Isolation of glutathione deficient mutants of the yeast Saccharomyces cerevisiae. Mutat Res 173, 117-120.

Kistler, M., Maier, K. \& Eckardt, F. (1990). Genetic and biochemical analysis of glutathione-deficient mutants of Saccharomyces ccerevisiae. Mutagenesis 5, 39-44.

Morita, R. (1993). Bioavailability of energy and the starvation state. In Starvation in Bacteria, pp. 1-24. Edited by S. Kjelleberg. New York: Plenum Press.

Meister, A. (1973). On the enzymology of amino acid transport. Science 180, 33-37.

Meister, A. \& Anderson, M. E. (1983). Glutathione. Annu Rev Biochem 52, 711-760.

Messenguy, F. (1976). Regulation of arginine biosynthesis in Saccharomyces cerevisiae: isolation of a cis-dominant constitutive mutant for ornithine carbamoyltransferase. J Bacteriol 128, 49-55.

Messenguy, F., Colin, D. \& Ten Have, J. P. (1980). Regulation of compartmentation of amino acids pools in Saccharomyces cerevisiae and its effect on metabolic control. Eur J Biochem 108, 439-447.

Nyström, T. (1993). Global systems approach in the physiology of the starved cell. In Starvation in Bacteria, pp. 129-150. Edited by S. Kjelleberg. New York: Plenum Press.

Ohsumi, Y., KItamoto, Y. \& Anraku, Y. (1988). Changes induced in the permeability barrier of the yeast plasma membrane by cupric ion. J Bacteriol 170, 2676-2682.

Payne, G. M. \& Payne, J. W. (1984). $\gamma$-Glutamyltransferase is not involved in the bulk uptake of amino acids, peptides or $\gamma$-glutamyl amino acids in yeast (Saccharomyces cerevisiae). Biochem J 218, 147-155.

Penninckx, M. J. \& Elskens, M. (1993). Metabolism and functions of glutathione in micro-organisms. Adv Microb Physiol 34, 239-301.

Penninckx, M. J., Jaspers, C. \& Wiame, J. M. (1980). Glutathione metabolism in relation to the amino-acid permeation systems in the yeast Saccharomyces cerevisiae. Eur J Biochem 104, 119-123.

Ramos, F., Thuriaux, P. \& Wiame, J. M. (1970). The participation of ornithine and citrulline in the regulation of arginine metabolism in the yeast Saccharomyces cerevisiae. Eur J Biochem 12, $40-47$.

Robins, R. \& Davies, D. (1981). Lack of correlation between GSH turnover and amino acid absorption by the yeast Saccharomyces cerevisiae. Phytochemistry 20, 1497-1499.

Szczypka, M. S., Wemmie, J., Scott Moye Rowley, W. \& Thiele, D. J. (1994). A yeast metal resistance protein similar to human cystic fibrosis transmembrane conductance regulator (CFTR) and multidrug resistance-associated protein. J Biol Chem 269, 22853-22857.

Received 4 December 1996; revised 31 January 1997; accepted 4 February 1997. 